\title{
Kurdistan's Economic Development: Exploring the Contribution of Economics Education
}

\author{
Waqar Ahmad ${ }^{1} \&$ Osman Sahin ${ }^{2}$ \\ ${ }^{1 \& 2}$ Department of Business Management, Faculty of Administrative Sciences, Tishk \\ International University, Erbil, Iraq \\ Correspondence: Osman Sahin, Tishk International University, Erbil, Iraq. \\ Email: osman.sahin@ishik.edu.iq
}

Doi: $10.23918 /$ ejmss.v1i2p39

\begin{abstract}
The newly formed Kurdistan region of Iraq (KRI) has embarked on a fast pace on economic development so as to give a great future to all its residents. Todaro \& Smith (2015) the great scholars on economic development give us the theoretical module consisting of Eight Goals ( $8 \mathrm{G}-\mathrm{ED}$ ) that constitute holistic economic development for a region or a country. This requires that graduates in both public and private universities taking courses in economics education should be aware of these $8 \mathrm{G}$ - ED. Hence, both the government and citizens can have an agreed understanding of what makes economic development relevant to $21^{\text {st }}$ century. This qualitative paper will demonstrate how the integration of governance and economic education to bring about concrete changes in the policies as well as business practices in Kurdistan will make of residents take in the economic for the welfare of the region. The overall aim of this study is to determine in what ways economic education with $8 \mathrm{G}-\mathrm{ED}$ can contribute constructively to Kurdistan economic development.
\end{abstract}

Keywords: Kurdistan Economic Development, Economic Education, Higher Education, 8 Goals of Economic Development

\section{Introduction}

The improvement of the quality of life has always been aspired for by the people in the national context, the attainment of this aspiration is facilitated through the framework of national development (Khan, 2019). As such, the Kurdistan government's foremost agenda is national development. This development agenda sets the direction for the mission, aims and activities of all sectors of the society including education. Crowley and Swan (2018) 
stated that the educational aims and goals are set so that it is in line with national development efforts. Therefore, a field of study or a discipline is deemed relevant, important and thus promoted based on how it supports the nation's development goals. It is to this end that the role and contribution of economics to national development must be determined.

This paper began by defining the concept and definition of economic development and education economics. It then begins to define the role of economic education and determine its specific contribution to national development policies and strategies. The concepts used are derived largely from selected papers from popular magazines and books. The vision of economic development is realized through different strategies for international effectiveness and public empowerment.

Do not ignore the way economic education issues related to economic development and educational research have been embodied in the concept of intellectual youth in the short term. Marcos (1980) determines they are still unrealistically linked to a common technology incorporated in field development theory and critical evaluation of preparation. In fact, the priorities of one-man preparedness and openness are generally broken peacefully using the critical philosophy of research obtained from: consideration of the teaching year for individual and social applications, the degree of inverse government spending, the cost of preparation, the degree of education of the country and the relationship between its currency and the degree related to the degree and social progress, and the idea of a media structure. Value of the level of competence in the public, from graduation class to adult, to prepare plan SACO minority offer unnecessary price assessment Cana and more.

These tests enabled researchers to determine the nature of the education framework in the country and understand the importance of school evaluation and further education and distinguish them in the working relationship between nation education and improvement. Perhaps it is, this research is not exhaustive. Of course, all that is clear and available, exploring the budget's field of view for scientists is not ready to provide an adequate response to the issue addressed by economic education (JECC 1976).

These are certainly not fruitful, profitable, socially commendable, and appropriate plans for criticism. (Valero \& Reenen, 2018) stated that the reformatories can be attributed to the theoretical foundations of this type of study and to scientists who have specialized 
economic institutions for the actual structure of the education budget portion. Economic education could also part of economic development if society will aware the problems. However, the economic education is very useful to implement in economy to provide the sufficient information about development in Kurdistan.

\subsection{Research Questions}

- What is the correlation between Kurdistan economic development and higher education?

- What should be the content of economics education in Kurdistan?

- How economics education can contribute to Kurdistan economic development?

\subsection{Limitations and Significance of the Study}

The backgrounds of this research are to substitute a high understanding of the demonstration techniques that can be used in Kurdistan's economy and economic education and can ultimately better understand economic subjects through their teaching methods. This paper focuses on looking for proven and viable issues in today's economic setting and adaptation. Through the overview, expand a pair of understandable performance methods with economic education and expand how these systems correspond to different academic styles of clothing. All possible learning arrangements will have the option of teaching them exercises that benefit from a dim learning method and are related to the subject being presented. It should be noted that the empowerment of techniques carried out at university level was investigated on economic education. Investigation is imposed at the discretionary level.

2. Articles derived from the tool's mini-web menus can be used for an event that was available in a standard branch or library.

3. A person sentenced for evaluation has modified an emailed survey. He could not meet her. This is seen as a restriction because in the event of confusion, individuals cannot quickly prepare to express themselves. Or maybe, follow-up letters; with more information, gradually important details, just as explained, are sent to individuals. 


\section{EJMSS}

\section{Eurasian Journal of Management \& Social Sciences}

\section{Literature Review}

\subsection{Economic Education}

Economic education is critical since it is basic to the future prosperity of our Kurdistan economy. The inspiration driving economic education is to make skilled locals and convincing boss. As shown by James Calderwood in the article "What is Economic Education," these two qualities anticipate that understudies should have the alternative to appreciate and settle on mulled over choices about major money related request standing up to society and themselves as people from that society (Calderwood, 1981, p.33).

A large number of modern budget problems can be solved if you complete a course in economics and teaching economically. Critical education is an important topic that will be the common neglect of a large number of schools in our country. The survey was compiled by the Kurdistan Demographic Survey, 2018. The main headline "Demographic Survey: Iraqi Kurdistan Region" is still that education in our country's schools should be a reality. Certainly, progress has been made in teaching economics over the past few years, although more work is needed to focus on economics in our K-12 education system. Steps to be taken for smelting; these subjects require free and independent courses as part of the alternative school graduation requirements and testing the level of educational commitment. One of the current problems with funding guidelines is the use of framework trainers to demonstrate the subject. Most economic education has long been in traditional techniques. There will be a special strategy for chalk and speaking, a traditional education technique where teachers conduct incomplete studies and use writing boards to present a model or outline.

\subsection{Economic Development: 8G-ED}

Economic reform is clearly based on the practical knowledge of some irregular states, which is the determining determinant of the country's return and exchange and includes significant reform of the system's ability to effectively achieve external development. According to (Ahmad, 2019) 8G-ED has done important work in the progress of Kurdistan and for example: prosperity and livelihood, basic and wise preparation increases both labor productivity, natural and urban; provides collaborative guidance, including skills, competence and strength of manager cut; higher preparation improve basic science and ensure fit for ingresses development and progress in family change and economic 


\section{EJMSS Eurasian Journal of Management \& Social Sciences}

development. Assistant and the third also address the basic foundations for the reform of infrastructure, government, law and budget systems. Small-scale and full-level test confirmations illuminate these relationships. Todaro and Smith (2015) stated that the minimized level that the various value indicators show that the added value of the setting added to interest is related to the extended length, with a large degree of direction varying the speed of return. Profits from basic teaching will generally be more important than returning to elective and third education.

According Todaro and Smith (2015) 8G-ED means are the following are:

1. Quality of life

2. Creation of capacity

3. Optimum utilization of Resources

4. Make citizens more competitive

5. Encourage youth to education

6. Making local economy more efficient

7. Attract new employers

8. Access outside sources of capital

Education is also an important supporter of innovative capabilities and special changes in the industry. A rigorous testing of fashion and buildings in Sri Lanka, which shows only one model, showed that the tendency and level of readiness of workers and business philosophies is clearly linked to the speed of discrimination identified in the company (Deraniyagala, 1995).

Economic education alone cannot, of course, change the economy. Other important factors of economic performance include the policy environment and the size and quality of investments. However, the level of human development also affects these factors. The education of policymakers and managers should influence the decision-making process and the quality of investment decisions: moreover, any system has the potential to increase domestic and foreign investment.

\subsection{Universities Profile in Kurdistan}

The Kurdistan Region currently has about 19 state and state advanced private educational bases. There are two semesters each academic year. The standard research deadline by 
which to complete the degree program, however, is eight to ten semesters at the college. The above-mentioned institutions include colleges and similar advanced educational institutions, for example specialized colleges, full colleges and specialized institutions at the college level (e.g., drugs, sports, organizational exams, logic and philosophy). Only colleges and relative organizations are currently eligible for a doctorate. The female score is $48 \%$. Education in the Kurdistan Region is free because there is no educational cost. According to MHERS (2018) Kurdistan Region has set up a college and two private colleges from the State Fund.

Table 1: Private and Public Universities in KRI

\begin{tabular}{|c|l|c|l|}
\hline Sr.No. & \multicolumn{1}{|c|}{ Private Universities } & Sr. No. & \multicolumn{1}{|c|}{ Private Universities } \\
\hline 1 & $\begin{array}{l}\text { American University of Iraq in } \\
\text { Sulaimani }\end{array}$ & 11 & $\begin{array}{l}\text { Komar University of Science and } \\
\text { Technology }\end{array}$ \\
\hline 2 & $\begin{array}{l}\text { Branch of VSB-Technical } \\
\text { University Ostrava in Erbil }\end{array}$ & 12 & Bayan University \\
\hline 3 & $\begin{array}{l}\text { University of Human } \\
\text { Development }\end{array}$ & 13 & Tishk University \\
\hline 4 & Nawroz University & 14 & Tishk University- Sulaimani \\
\hline 5 & Knowledge University & 15 & Catholic University \\
\hline 6 & Lebanese French University & 16 & $\begin{array}{l}\text { Qala College for Religious Studies/ } \\
\text { Erbil }\end{array}$ \\
\hline 7 & Cihan University- Erbil & 17 & $\begin{array}{l}\text { Goyzha College for Religious } \\
\text { Studies/ Sulaimani }\end{array}$ \\
\hline 8 & Cihan University- Sulaimani & 18 & $\begin{array}{l}\text { Qaiwan University for practical } \\
\text { Sciences/ Sulaimani }\end{array}$ \\
\hline 9 & Cihan University- Duhok & 19 & $\begin{array}{l}\text { American Stratford University- Erbil } \\
\text { Campus }\end{array}$ \\
\hline 10 & International University Erbil & & \multicolumn{2}{|l}{} \\
\hline
\end{tabular}




\section{EJMSS Eurasian Journal of Management \& Social Sciences}

\section{Material and Methods}

\subsection{Data Collection and Data Analysis}

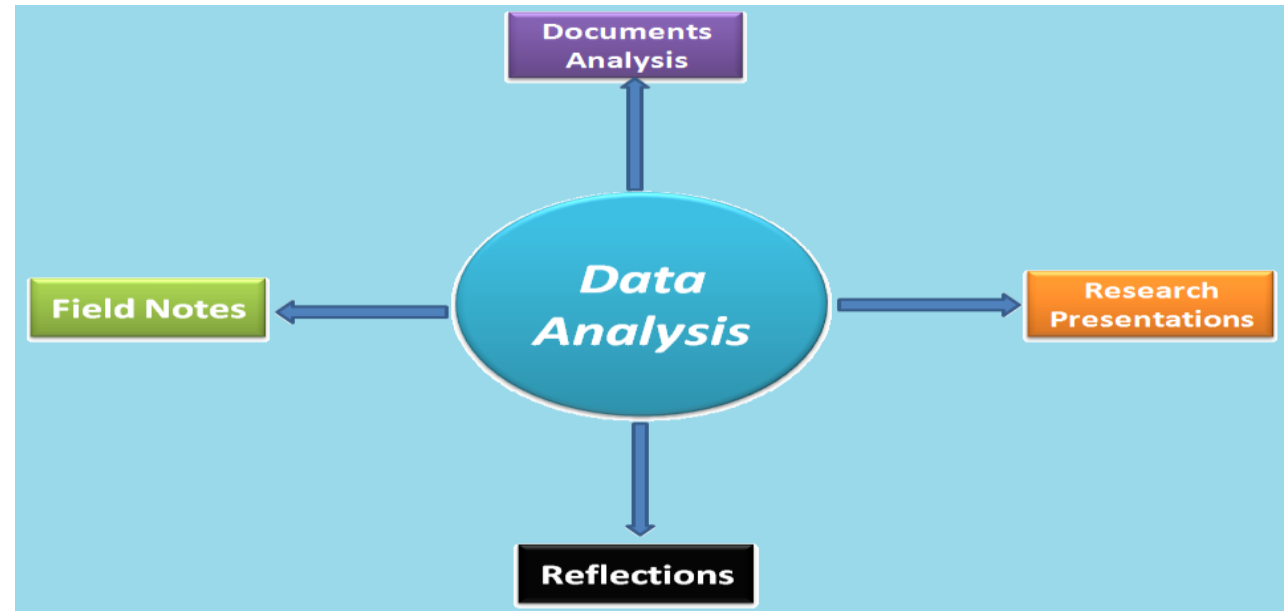

Figure 1: Data sources

\subsection{Data Analysis}

This study is called exploratory research from the point of view of the purpose of the study. This is the time when evaluation involves the purpose of either examining a lesser known area or exploring the possible consequences of conducting a special research study. True, when the exam ends by choosing its craft, it is also called a general knowledge study or an experimental study. This is usually done when a researcher needs to explore areas where no education is taught, as well as areas to be explored. A small-scale study should be carried out if it justifies termination of the application evaluation.

In the light of the outcome of the assessment during the exploratory evaluation, the full report is issued. Investigative assessments are also required to create and improve testing tools and testing processes. The goal of a research study could be to become a mastermind in the perspective class, and ultimately the majority of exams are a combination of three. That is, it covers the fields of expression, associations and educational research. In this book, the proposed guidelines for writing a research report encourage you to incorporate these aspects. (Kumar, 2011). 


\section{EJMSS Eurasian Journal of Management \& Social Sciences}

\section{Results and Findings}

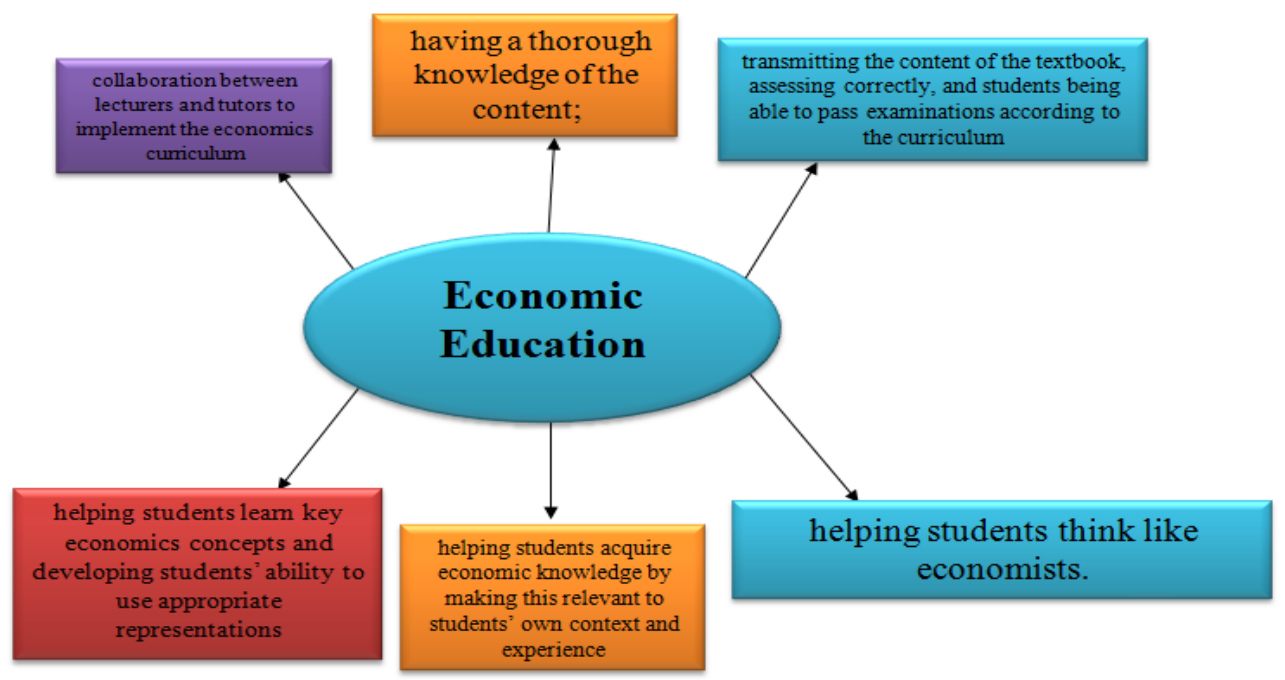

Figure 2: Findings about economic education

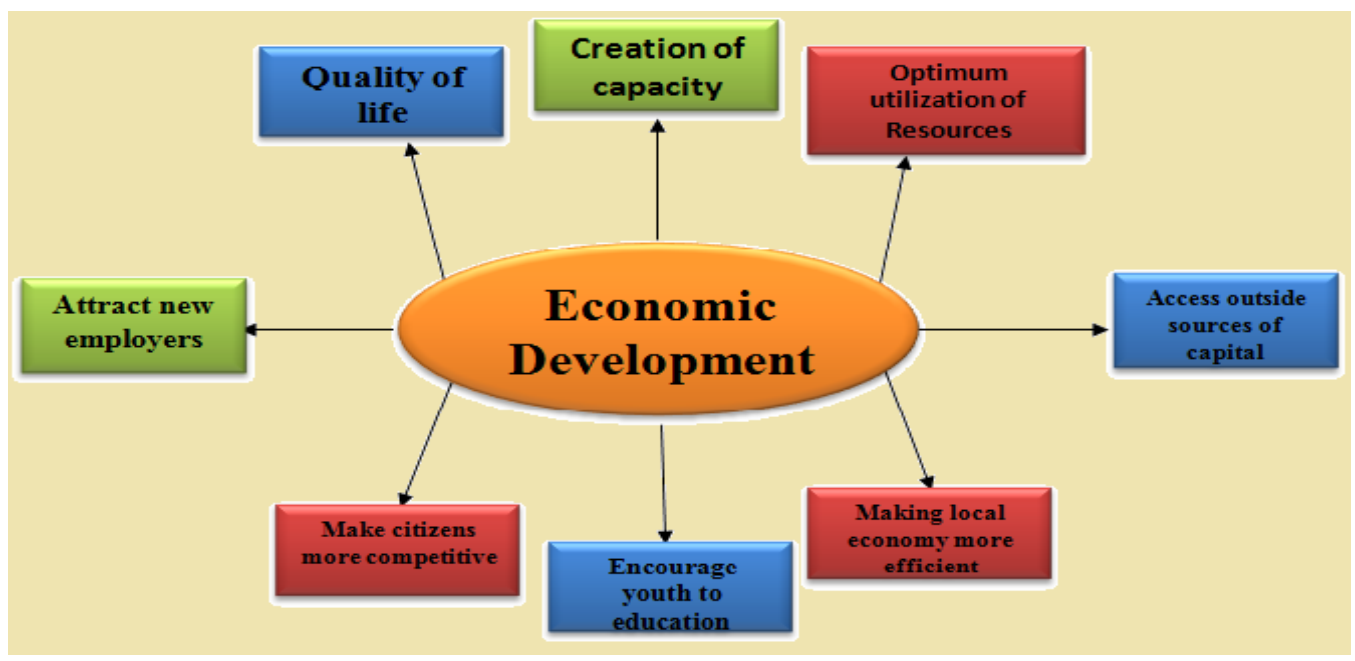

Figure 3: Findings about economic development 


\section{EJMSS}

\section{Eurasian Journal of Management \& Social Sciences}

\subsection{Discussion}

Most researchers in the economic guidance point out that the development of monetary efficiency is generally identified as the metro's main motivation for education in economic aspects (Crowley \& Swan, 2018). Anyway, as we asked at the beginning: what kind of economic evaluators are at the forefront of education for the economic side? Like other social research disciplines, economic actors develop clear information, abilities and behaviors that demonstrate a clear type of metro behavior. Why can retarded people use critical education in their lives in their city? To address this inquiry, we have defined definitions of participatory and equal economic citizenship. A fourth major example was the identification of Malian citizens and the consideration of the problems of demand-based education in economic aspects.

According to the results, we understand two reasons why this work is important for economic education. Most importantly, these initial examples of the monetary objective of the municipality give a more pronounced accuracy. Second, these models offer more visible potential results for understudies to apply economic aspects to their live competitions. Scientists view economic efficiency as citizenship education in the region in education economic aspects that carry precision for civilian purposes to teach economics. Although this trend is clear, the range of ways in which economic efficiency can be applied to city life is not well described. The historical education and civic education intensified the reason for their city because of social research in the Kurdistan environment, and economic matters neglected to do so in a similar way. An unexpected opportunity for teachers to place the concept of monetary education in its smallest structure, it may really depend or perhaps recognize the type of economic citizenship.

However, we have nitty gritty how monetary proficiency can be utilized in the administration of each of the four citizenship classes. In perspective on these citizenship models, money related viewpoints education can manufacture open entryways for their understudies to consider how they use their fiscal data to choose sound individual decisions, to participate in total movement, to fight against budgetary lopsidedness, or to develop an end consequent to contemplating different points of view. At the point when economic aspects teachers are progressively unequivocal and deliberate about the metro points of their guidance, they can furnish their understudies with increasingly solid uses of economic aspects content. Educators can push understudies to consider the enormous 
number of ways a budgetary issues education can inform their life outside with respect to universities. This articulation is particularly critical considering the qualification understudies feel between learning educational money related thoughts and the realistic utilization of monetary models. Moreover, these models are not totally unrelated nor are they fundamentally progressive. Economic reasoning undergirds every model classification and various circumstances loan themselves to various city authorizations. Understudies can surely profit by and by dependable practices that advance individual efficiency and money related duty.

The representatives need to understand, regardless of how they engage in hidden activities, or as valuations, regardless of where they take place in the rest of the business structures. Finally, teachers from the money related positions need agents to measure reports, form conflicts, and conduct deliberative debates on economic issues. We think that all of these priorities identify qualitative data with big data, capabilities, and form. (Luca \& Gabriella, 2014) stated that teaching and learning from these models can positively influence the progress of global critical citizenship. However, these models are well morally incompatible with one another.

On the larger side, economic citizenship has been promoted before participation and has long been reliable using market system mechanisms to achieve positive results, either individually or through large movements with less concentration. In large cases, it urges agents to look for rewarding ways of working within the current framework. Stocks are regulated and economic trains offer economic traction on different routes. The Arcade Framework study is about creating an existing property rights mechanism, while achieving social-economic responsibility can be used to allow for the implementation of increasingly aggressive monetary cycles in governance. These are important concerns for educators and teachers. We focus a large part of the content of recognized economic topics on working intelligently and efficiently within the market.

Economic prospects or models therefore grow as irreversible structures contrary to explicit interpretations of human behavior. Organizations do not have sufficient opportunities to understand how these models are in real situations or to consider competing models for compromise on valuable options. At this point when understudies are involved in organizing economic screening, they can discuss sensitivity and imagine how the economy can be unprecedented. The Economic Citizenship Model is prepared for how teachers can 
withdraw economic examinations in broader monetary examinations. The pricing and investigative Economic Citizenship Act should push controls to move away from the monetary credit model. Students in this system only benefit from a market economy unlike their results.

\section{Conclusion}

There exists a direct correspondence between economics education and national development stemming from shared goals. The goal and true measure of development is the improvement of the quality of life of the people. Likewise, economics education studies micro- and macro- economics for the purpose of equipping them to improve their lives. Focusing on basic needs and broadening its scope through its integrative perspective and approach on all aspects of family living for a better life, home economics has a vital position in national development.

As a catalyst for change towards national development, economics education tries to maintain a stable rate of change for progress while initiating changes and helping citizens adapt to these changes. The contributions of economics education to the development agenda of the country are extensive. Economic education relates to almost all the sectorial strategies planned to achieve the desired development targets by 2020 .

Knowing and understanding its position in affecting national development, Sen. Orly Mercado in his speech at a convention of economic education (1995) said that "economic education should enjoy the prominence it so richly deserves." But however great and grand the role appears to be, it only becomes valid by what we do to actualize it. The role lives in us. In the final analysis, what people will see, and re- member is not the role and contribution of the discipline of economic education but our individual role and contribution as economic educators in making life better for all.

\section{References}

Ahmad, W. (2019). The role of private universities in the economic development of Kurdistan: An explanatory study. ICABEP, Iraq. doi: 10.23918/ICABEP2019p32.

Calderwood, J. D. (1981). What is economic education? Consumer Education and Economic Education in the Public Schools, 34-35. 


\section{EJMSS Eurasian Journal of Management \& Social Sciences}

Cameron. M. P. (2018). What kind of economic Citizen? A Comment. Education Sciences: Educ. Sci., 8, 136; doi: 10.3390/educsci8030136.

Crowley, R. M., \& Swan, K. (2018). What kind of economic citizen? An analysis of civic outcomes in U.S. Economics Curriculum and Education Materials, Education Sciences: Educ.Sci. 2018, 8, 95; doi: 10.3390/educsci8030095.

Deraniyagala, S. (1995), Technical Changes and efficiency in Sri Lanka's Manufacturing Industry. D. Phil, Oxford.

Gabriel, F. S. (2018). The role and contribution of home economics to national development, The UP Journal of Home Economics, 25, 21-34.

JCEE (1976). Framework of basic economic concepts and generalization, Joint council on economic education: New York, UK.

Kumar, R. (2011). Research Methodology. SAGE Publication Ltd.

Luca, R., \& Gabriella, A. (2014). The economics of education as educational science. Procedia - Social and Behavioral Sciences 116 (2014), 2059 - 2063.

Marcos, F. (1980). IFHE Congress. UP Home Economics Journal, 8 (1).

Todaro, M., \& Smith, S. (2015). Economic development. Oxford: Oxford Publishing House.

Valero, A., \& Reenen, J. (2018). The economic impact of universities: Evidence from across the globe. Economics of Education Review, 68, 53-67. 